\title{
A CELL-FREE TESTING PLATFORM TO SCREEN CHEMICALS OF POTENTIAL NEUROTOXIC CONCERN ACROSS TWENTY VERTEBRATE SPECIES
}

\author{
Adeline Arini, ${ }^{\mathrm{a}, \mathrm{b}}$ Krittika Mittal, ${ }^{\mathrm{a}, \mathrm{b}}$ Peter Dornbos,,${ }^{\mathrm{a}, \mathrm{c}, \mathrm{d}}$ Jessica Head, ${ }^{\mathrm{a}}$ Jennifer RutKiewicz, ${ }^{\mathrm{a}, \mathrm{e}}$ \\ and NILADRI BASU ${ }^{\mathrm{a}, \mathrm{b}, *}$ \\ ${ }^{a}$ Department of Environmental Health Sciences, University of Michigan, Ann Arbor, Michigan, USA \\ ${ }^{\mathrm{b}}$ Faculty of Agricultural and Environmental Sciences, McGill University, Montreal, Quebec, Canada \\ ${ }^{\mathrm{c}}$ Department of Biochemistry and Molecular Biology, Michigan State University, East Lansing, Michigan, USA \\ ${ }^{\mathrm{d}}$ Institute for Integrative Toxicology, Michigan State University, East Lansing, Michigan, USA \\ ${ }^{\mathrm{e}}$ ToxServices, Ann Arbor, Michigan, USA
}

(Submitted 8 February 2017; Returned for Revision 9 March 2017; Accepted 5 June 2017)

\begin{abstract}
There is global demand for new in vitro testing tools for ecological risk assessment. The objective of the present study was to apply a set of cell-free neurochemical assays to screen many chemicals across many species in a relatively high-throughput manner. The platform assessed 7 receptors and enzymes that mediate neurotransmission of $\gamma$-aminobutyric acid, dopamine, glutamate, and acetylcholine. Each assay was optimized to work across 20 vertebrate species ( 5 fish, 5 birds, 7 mammalian wildlife, 3 biomedical species including humans). We tested the screening assay platform against 80 chemicals (23 pharmaceuticals and personal care products, 20 metal[loid]s, 22 polycyclic aromatic hydrocarbons and halogenated organic compounds, 15 pesticides). In total, 10800 species-chemical-assay combinations were tested, and significant differences were found in 4041 cases. All 7 assays were significantly affected by at least one chemical in each species tested. Among the 80 chemicals tested, nearly all resulted in a significant impact on at least one species and one assay. The 5 most active chemicals were prochloraz, $\mathrm{HgCl}_{2}$, Sn, benzo $[a]$ pyrene, and vinclozolin. Clustering analyses revealed groupings according to chemicals, species, and chemical-assay combinations. The results show that cell-free assays can screen a large number of samples in a short period of time in a cost-effective manner in a range of animals not easily studied using traditional approaches. Strengths and limitations of this approach are discussed, as well as next steps. Environ Toxicol Chem 2017;36:3081-3090. (C) 2017 SETAC
\end{abstract}

Keywords: Risk assessment Toxicity testing Screening assay Ecotoxicology Comparative

\section{INTRODUCTION}

Thousands of chemicals and environmental samples need to be evaluated for regulatory purposes. However, the current testing paradigm is challenged as it mainly relies on animal studies that are inefficient in the cost of time, money, and animal lives [1-3]. These limitations were highlighted by the US National Research Council in their report "Toxicity Testing in the 21st Century: A Vision and a Strategy" [4]. A major recommendation of the National Research Council report was to develop and utilize in vitro tests to assist in assessing the potential risk associated with exposures to chemicals and complex environmental samples. In particular, the report articulated the need to establish in vitro platforms that can screen a large number of chemicals and samples (thousands) in a relatively short period of time (days to weeks) and in a relatively cost-effective manner.

To date, the development and application of in vitro tools for testing chemicals and environmental samples have been primarily focused on the human health community. Unfortunately, such developed tools and the resulting information are of limited use within the ecotoxicological sciences where many more species and environmental contexts come under scrutiny. Relatively few in vitro testing tools exist for standard ecotoxicological test species, with even fewer available for native species of ecological relevance. This is

This article includes online-only Supplemental Data.

* Address correspondence to Niladri.basu@mcgill.ca

Published online 8 June 2017 in Wiley Online Library

(wileyonlinelibrary.com).

DOI: $10.1002 /$ etc. 3880 problematic because the extrapolation of results across species (i.e., from standard test species to native species of ecological relevance) introduces tremendous uncertainty, as does extrapolation from controlled laboratory tests to realworld environments [5]. For example, native bird species [6] and fish [7] can be more sensitive and/or respond differently to chemicals than standard laboratory models. Such differences complicate decision-making and often necessitate additional testing.

There is a great need to accelerate the development and application of in vitro toxicity testing tools for the purposes of ecological risk assessment [5]. Cell-free assays represent a viable possibility (A. Arini, McGill University, Montreal, Quebec, Canada, unpublished data). Cell-free assays are simplified in vitro platforms that can help evaluate the potential effects of a chemical or environmental sample on biochemical processes, such as ligand-receptor binding or an enzymatic rate of reaction. A great advantage of cell-free assays is that they are amenable for use from any species from which tissue can be obtained. This versatility is especially useful for ecological species that are difficult to maintain under laboratory conditions and which lack proven cell-based tools. Furthermore, cell-free assays have formed an integral component of the US Environmental Protection Agency's (USEPA's) ToxCast program. ToxCast is an ambitious endeavor that is currently comprised of nearly 1000 in vitro technologies/assays aimed at providing cost-effective and rapid approaches to screen for changes in biological activity in response to chemical exposure mainly for the purposes of human health $[8,9]$.

We have previously utilized cell-free neurochemical assays to screen real-world effluent samples from pulp and paper 
mills [10] and wastewater-treatment plants [11], to compare responses between mammalian wildlife (mink, river otters) and biomedical models [12], and to study potential responses in an Arctic marine mammal (ringed seals) that is difficult to study in a controlled setting [13]. In the present study we scaled up our activities and applied a set of cell-free neurochemical screening assays to serve as a screening platform to evaluate many chemicals across many species. Specifically, the platform assessed 7 key receptors and enzymes that mediate neurotransmission of $\gamma$-aminobutyric acid (GABA), dopamine, glutamate, and acetylcholine. Each assay was optimized to work across 20 diverse vertebrate species ( 5 fish, 5 birds, 7 mammalian wildlife, and 3 biomedical species including humans). We tested the screening assay platform against 80 notable chemicals of environmental concern to serve as a proof of concept that this could be a new approach of particular interest to the community.

\section{METHODS}

\section{General overview}

The overall experimental design mirrors the approach taken by the USEPA's ToxCast program for the biochemical screening of chemicals [8,9]. In short, a single concentration $(50 \mu \mathrm{M})$ of each chemical $(n=80)$ was tested in each cell-free in vitro assay $(n=7)$ for each species $(n=20)$. All assays were performed in 96-well microplates. Each microplate consisted of a single assay-species pair. All assay plates contained positive (assay-specific) and negative (buffer-only) controls, as well as pooled controls to address inter- and intraplate variability.

\section{Brain tissues}

Brain tissues were obtained from fish ( $n=5$ species), birds ( $n=5$ species), mammalian wildlife ( $n=7$ species), and biomedical organisms ( $n=3$ species including humans) from a number of sources (Supplemental Data, Table S1). For each species, brain tissue from a minimum of 6 individuals was pooled, with efforts made to ensure that males and females were equally represented. Pooling was used as a way to minimize potential interindividual differences, which can be pursued in future work. Whole brains were sampled for all species except for the mammalian wildlife and humans in which the cerebral cortex region was sampled. Cell membranes (for receptor assays) and homogenates (for enzyme assays) of pooled brain regions were prepared according to previous reports [14]. Aliquots were frozen on dry ice and stored at $-80^{\circ} \mathrm{C}$ until required for assays.

\section{Neurochemical receptor binding assays}

Radioligand binding to the GABA receptor benzodiazepine site (GABA-BZ), muscarinic acetylcholine receptor (mAChR), $\mathrm{N}$-methyl-d-aspartate receptor (NMDA), and dopamine-2 (D2) receptors was performed using species-specific cellular membranes plated in microplate wells containing a $1.0 \mu \mathrm{M} \mathrm{GF} / \mathrm{B}$ glass filter (MultiScreenHTS) according to published methods [10,11]. Briefly, $30 \mu \mathrm{g}$ of cellular membrane preparations were resuspended in $100 \mu \mathrm{L}$ of assay-specific buffer (see Supplemental Data, Table S2 for specific methodological details) and added to preconditioned microplate wells. Membrane preparations were incubated under gentle agitation with receptor-specific radioligands for 30 to $120 \mathrm{~min}$ depending on the receptor-ligand pair and subsequently terminated by vacuum filtration. Filters were washed 6 times with buffer and dried overnight before being soaked for $48 \mathrm{~h}$ in $30 \mu \mathrm{L}$ of OptiPhase Supermix Cocktail (Perkin Elmer). Radioactivity retained by the filter was quantified by liquid scintillation counting in a microplate detector (Wallac 1450 Microbeta Trilux; PerkinElmer).

The effect of test chemicals (see section Test chemicals) on receptor binding was determined by adding the chemical to each well just after adding the radioligand. All chemicals were assayed in quadruplicate with slow shaking for different incubation times and temperatures (Supplemental Data, Table S2). The total binding was determined by incubating 6 wells/microplate with buffer instead of test chemical. Nonspecific binding was determined by incubating 6 wells with unlabeled assay-specific displacer. Intra- and interplate variations in receptor binding were determined by use of internal controls.

\section{Neurochemical enzyme activity assays}

Enzymatic activity of glutamine synthetase (GS) was measured in homogenates as described by Rutkiewicz et al. [15]. Briefly, assay buffer (50 mM imidazole, $12.5 \mathrm{mM}$ sodium arsenate, $0.8 \mathrm{mM}$ ADP, $25 \mathrm{mM}$ l-glutamine, $25 \mathrm{mM}$ hydroxylamine, $1 \mathrm{mM}$ manganese chloride) was added to each well followed by the test chemicals in triplicate. In control wells, chemicals were replaced by Tris buffer (negative control) or by methionine sulfoximine $(10 \mathrm{mM})$ as a positive control. Next, tissue homogenates were added rapidly to initiate the reaction. Following incubation at $37^{\circ} \mathrm{C}$ for $30 \mathrm{~min}$, a ferric chloride stop solution was added to each well. Absorbance was read at $540 \mathrm{~nm}$ in an HTS 7000 Plus Bioassay Reader (PerkinElmer). Enzyme activity was determined by a colorimetric assay measuring the production of $\gamma$-glutamyl hydroxamate from glutamine.

The activity of monoamine oxidase (MAO) was measured in homogenates according to published methods [10], with slight modifications. Briefly, assay buffer $(50 \mathrm{mM}$ tyramine, $50 \mathrm{mM}$ 10-acetyl-3, 7-dihydroxyphenoxazine, $100 \mathrm{mU}$ horseradish peroxidase) was added to each well, followed by the test chemicals which were assayed in triplicate. As a negative control, chemicals were replaced by Tris buffer, a mix of $100 \mu \mathrm{M}$ chlorgyline and/or $100 \mu \mathrm{M}$ deprenyl, and $5 \mu \mathrm{M} \mathrm{H}_{2} \mathrm{O}_{2}$ was used as a positive control. Next, tissue homogenates and Tris buffer were added to each well to initiate the reaction. Plates were incubated at room temperature for $30 \mathrm{~min}$, following which fluorescence $\left(\lambda_{\mathrm{ex}}=530 \mathrm{~nm}, \lambda_{\mathrm{em}}=590 \mathrm{~nm}\right)$ of resorufin was measured every minute for $15 \mathrm{~min}$ in an HTS 7000 Plus Bioassay Reader. Enzyme activity was calculated as the production of resorufin per minute per milligram of protein.

The activity of the acetylcholine esterase (AChE) was measured following the Ellman protocol. Briefly, Ellman reagent and 5-5'-dinitrobis-2-nitrobenzoate (DTNB, $1.125 \mathrm{mM}$ ) were added to each well. For a negative control, $20 \mu \mathrm{M}$ galanthamine replaced the DTNB. Next, test chemicals were added in triplicate. Reactions were initiated with the addition of tissue homogenate and $1.875 \mathrm{mM}$ acetylthiocholine iodide to each well. Absorbance was read in the HTS 7000 plate reader every $30 \mathrm{~s}$ for $5 \mathrm{~min}$ at $405 \mathrm{~nm}$ immediately after adding acetylthiocholine iodide. Enzyme activity was determined by a colorimetric assay measuring the production of 5-thio-2-nitrobenzoic acid per minute and per milligram of protein.

\section{Test chemicals}

As a proof-of-concept activity we focused on 80 notable environmental chemicals which were selected considering the following: 1) chemical properties that make them persistent, bioaccumulative, and toxic to fish, wildlife, and humans as defined in the Great Lakes Water Quality Agreement Annex 
12 [16]; 2) identification by experts as an emerging chemical of concern [17]; 3) listed as a priority substance by the Comprehensive Environmental Response, Compensation, and Liability Act of 1980 [18], also known as Superfund; 4) commonly detected in waterways across the United States [19]; and/or 5) biomonitored in US residents as part of the Centers for Disease Control's National Health and Nutrition Examination Survey [20]. The chemicals were grouped into 4 classes (number of chemicals in parentheses) as follows: pharmaceuticals and personal care products $(n=23)$, metal(loid)s $(n=20)$, polycyclic aromatic hydrocarbons (PAHs) and halogenated organic compounds $(n=22)$, and pesticides $(n=15)$. Specific details on each of the chemicals, such as Chemical Abstracts Service number, supplier, and solvent, are provided in Supplemental Data, Table S3. All tested chemicals were $>90 \%$ pure, and many were predissolved in a range of solvents (i.e., DMSO, methanol, hexane, acetone, nitric acid), all of which we have previously tested for potential interferences at $5 \% \mathrm{v} / \mathrm{v}$ ratios with no discernable effects. Chemicals were tested against the receptor assays in quadruplicate (i.e., each chemical was tested in 4 different microplate wells for each species-assay pairing), and for enzyme assays each chemical was tested in triplicate.

\section{Data analyses}

All assay results were inputted into an MS Excel document that served as the main database for the present study. Preliminary data analysis included tabulation of descriptive statistics for all measurements to understand the basic features of the data set. Because an edge effect was observed in some of the microplates, we decided to use 3 of the 4 replicates for all chemical-assay-species data set (i.e., removed data from the outer edge wells). The observation of an edge effect in particular assay plates (which we were able to correct for) is not consistent with previous studies performed in our or our colleagues' laboratories; we discuss the edge effect in the section Data quality. Following removal of edge-based wells, all raw data points were normalized to intraplate controls that were not exposed to any test chemicals.

All data are represented as mean \pm standard error unless otherwise indicated. The critical level of significance for all statistical analyses was set at $\alpha=0.05$. Because of the skewed distribution of the data, nonparametric statistical tests were performed. A Kruskal-Wallis analysis of variance was performed to identify chemicals that elicited a response that was significantly $(p<0.05)$ different from that of the negative control in the same plate. Chemical-assay-species combinations that caused either significant activation or inhibition of a particular neurochemical receptor binding or enzyme activity were flagged and are reported in the present study as appropriate.

To explore for relationships and clustering among focal variables (chemicals, species, assays), hierarchical analyses were performed using Gene Cluster 3.0 and Java TreeView. The findings were represented visually as heat maps with uncentered Pearson correlations and reporting the maximum distance between 2 items among all pairwise comparisons. The correlation $(r)$ measured at key cluster nodes is provided.

\section{RESULTS AND DISCUSSION}

\section{Data quality}

The present study was a relatively large screening study aimed as a proof of concept to show that the underlying approaches in past studies using a set of cell-free neurochemical screening assays could be scaled up and serve as a screening platform to evaluate many chemicals across many species. While the main goal of the study was met and useful data were obtained, there were 2 noteworthy aspects of data quality that require discussion. First, variability in responses within and across microplates occurs. In our past studies running these same assays, the variation within and across plates was generally $<20 \%$, as deemed by analyses of the internal pools. Such was the case in the present study for many assays except for receptor binding for D2 (32.4\%), GABA-BZ (29.7\%), and mAChR (22\%), and for enzyme activities for AChE (26.9\%), with the interplate variability indicated in parentheses. As mentioned, an edge effect was observed in some assay microplates. Although analytical precision upward of $30 \%$ is acceptable in many cases using microplates (e.g., Organisation for Economic Co-operation and Development H295R steroidogenesis assay), such variability introduces "noise" into the screening platform capabilities and needs to be carefully reviewed and considered when trying to identify "hits." Second, a pattern emerged in some of the receptor binding assays in which the top half of the microplate showed a higher signal than the bottom half. Troubleshooting was performed for over $1 \mathrm{yr}$ with steps taken to carefully inspect the microplates (e.g., lot numbers, discussions with the manufacturer), the equipment, and assay processes (e.g., multichannel pipettes, liquid handling and dispensing instruments, vacuuming plates) and to recalibrate the scintillation counter. The pattern was observed in $19.4 \%$ of the receptor binding plates. Despite this challenge, the data from the flagged plates were predictable (i.e., the increase in binding was consistent), so we applied numerical corrections to the resulting data. While these 2 issues do not diminish the overall goal of the study, they need to be carefully considered when interpreting the results from this particular study and monitored in future efforts using these assays. However, we note that in previous screening activities using similar assays by our group $[10,11]$ as well as in a subsequent study in preparation for publication (larger in scope than the current; i.e., screening USEPA ToxCast's E1K library), the 2 challenges above were not encountered.

\section{Data overview}

The general results of this chemical screening activity are summarized in Figure 1, with key summaries provided in Tables 1 and 2. In total, 10800 species-chemical-assay combinations were tested $(20$ species $\times 80$ chemicals $\times 7$ assays, though MAO and GS activities were only screened in a subset of samples). Of these 10800 species-chemical-assay combinations, significant differences were found in 4041 cases (37\% of total). This frequency of hits is more than reported in previous studies within the USEPA ToxCast program. For example, a study of 976 chemicals screened across 331 enzymatic and receptor signaling assays yielded active assaychemical pairs in approximately $2 \%$ of all cases [21]. Another ToxCast study on 309 chemicals evaluated across 292 biochemical targets reported that $10.3 \%$ of the assays were susceptible to being affected by 7 or more chemicals [8]. The relatively higher percentage of hits in the present study is not surprising as we purposefully selected well-known environmental chemicals, many of which are known neurotoxicants. Also, each of the 80 chemicals was tested against 20 species compared to the aforementioned platforms that are generally focused on testing single chemicals against single species through a range of assays. 


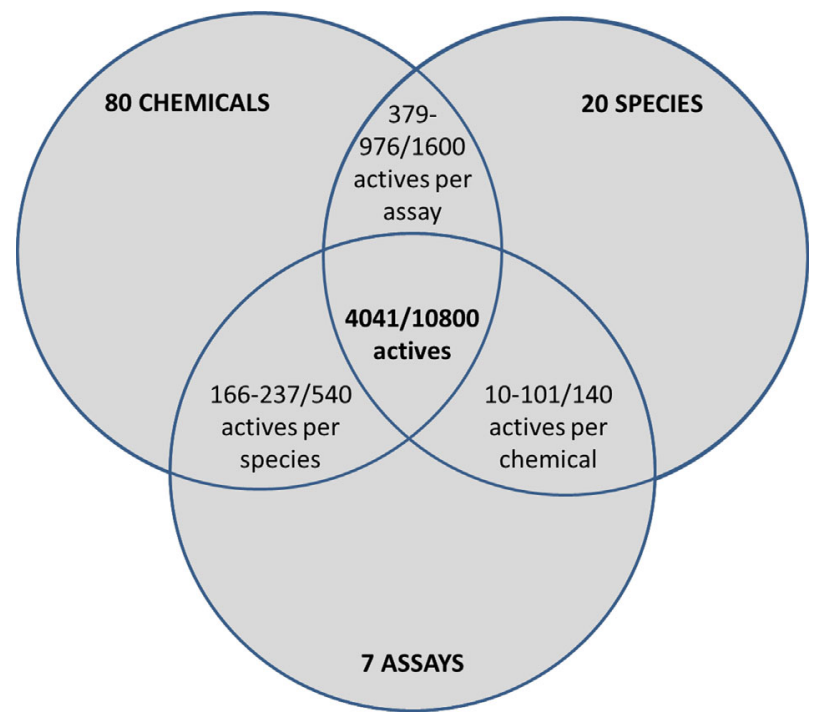

Figure 1. Venn diagram of the active "hits" among the 10800 chemicalspecies-assay triads studied.

The number of active chemical-assay pairs is presented Tables 1 and 2. All 7 assays were significantly affected by at least one chemical in each species tested. Among the 80 chemicals tested, nearly all resulted in a significant impact on at least one species and one assay (number active ranged from 71 to 80 chemicals depending on the species-assay pair).

\section{Test chemicals}

A total of 80 chemicals were tested, and each of them affected at least one species and one assay. The chemicals were categorized into 4 classes: pharmaceuticals and personal care products $(n=23)$, metal(loid)s $(n=20)$, PAHs and halogenated organic compounds $(n=22)$, and pesticides $(n=15)$; chemicals within each of these categories were active on an average of 48.1/140, 36.1/140, 56.8/140, and 50.1/140 species-assay pairs, respectively. In terms of number of species affected, the chemicals within the pesticide group were the most active, with $8.3 / 20$ species on average being impacted by each chemical, followed by pharmaceuticals and personal care products $(7.7 / 20$ species), metal(loid)s (6.9/20 species), and PAHs and halogenated organic compounds (6.2/20 species).

The 5 most active chemicals were prochloraz, $\mathrm{HgCl}_{2}, \mathrm{Sn}$, benzo $[a]$ pyrene $(\mathrm{BaP})$, and vinclozolin. Each of these 5 chemicals affected at least $60 \%$ of the species-assay pairs (Table 1). Other chemicals that affected at least $50 \%$ of the species-assay pairs studied included diethylstilboestrol, bisphenol A (BPA), malathion, anthracene, indomethacin, 17 $\alpha$-ethinylestradiol (EE2), ibuprofen, methylmercury, and methyl parathion. Chemicals that affected $<15 \%$ of the species-assay pairs studied included triclosan, cholesterol, fluoride, and caffeine.

Clustering was used to identify which chemicals acted most similarly in the cell-free neurochemical assays (Figure 2). The clustering was ordered by response potency with cells in Figure 2 ranging from red (negative values reflecting inhibition) to blue (positive values reflecting activation) in comparison to nonexposed samples. Four main clusters were identified and are briefly described. The strongest grouping of chemicals was found in cluster 1 . Cluster 1 had 11 chemicals which were all metal(loid)s (Cr, Cd, Mn, Co, Li, Ni, Al, Se, La, As, In; $r=0.85)$. Interestingly, $\mathrm{Hg}$ and $\mathrm{Pb}$ were not present in cluster 1 even though they were among the most active chemicals.
Similarly, prochloraz (another highly active chemical) was not found in any of the other clusters. Cluster 3 was another grouping that contained chemicals from the same class and in this case consisted of 11 pharmaceuticals and personal care products (gemfibrozil, triclocarban, diethylstilboestrol, dexamethasone, ketoconazole, EE2, ibuprofen, indomethacin, 17 $\beta$ trenbolone, fadrazole, trilostane; $r=0.51$ ). The other 2 clusters contained chemicals from across categories, though some similarities were noted within the clusters. Cluster $2(r=0.54)$ included well-studied organic pesticides (parathion, malathion, dieldrin, dichlorodiphenyldichloroethylene [DDE], glyphosate), PAHs (anthracene, fluoranthrene, phenanthrene, BaP), and halogenated compounds (Aroclors 1254, 1232, 1260, 1016). Cluster $4(r=0.67)$ included chemicals that were organophosphate flame retardants (tris[1-chloro-2-propyl] phosphate [TCPP], tris[2-chloroethyl]phosphate [TCEP], tricresyl phosphate [TCrP], tris[2-butoxyethyl]phosphate [TBEP], tris[1,3-dichloro-2-propyl]phosphate [TDCPP]) and certain personal care products (triclosan, cimetidine, cholesterol, caffeine, acetaminophen).

\section{Species comparisons}

The 80 chemicals and 7 assays resulted in 540 chemicalassay pairs tested for each animal species (Table 2). Across the 20 species studied, 166 to 237 (of 540) chemical-assay pairs showed significant results. Among the species, yellow perch (237), pilot whale (236), and humans (233) exhibited the highest numbers of chemical-assays pairs affected (number of chemical-assay pairs affected indicated in parentheses). There was no clear distinction in species differences (in terms of numbers of chemical-assay pairs affected) with respect to their taxonomic grouping, though we note that the 2 marine mammals (narwhals, 182/540; ringed seal, 166/540) had the fewest affected chemical-assay pairs. While these types of results do not permit valid or robust estimates of differences in species sensitivity to be calculated, there are few approaches that permit such a wide range of animals to be studied together; and the current work lays the foundation for future efforts that may help improve this aspect of testing across species.

The species-species clustering analyses showed high correlations among all species assayed, with only positive correlations measured as the $r$ value ranged from 0.25 to 0.94 (Figure 3). Some fishes and birds were highly correlated (king mackerel, chicken, zebra finch, goldfish, yellow perch; $r=0.83$ ), though in general there were no obvious groupings according to the different vertebrate groups (mammals, birds, fish, biomedical species) or other types of pairings (e.g., aquatic and terrestrial species). Rainbow trout exhibited the most differences with the others (34\% similarity averaged with other species), with the least similarity in responses found between rainbow trout and humans $(10.4 \%)$ and between rainbow trout and ringed seal $(25.2 \%)$. In contrast, the highest similarity was measured between mink and pilot whale $(82.5 \%)$ and between mink and bald eagle (79.9\%).

\section{Neurochemical assays}

The 80 chemicals were tested across 20 test species, thus resulting in 1600 chemical-species pairs per assay. The 2 assays that were most affected were GS and MAO with 730/1200 and $614 / 1200$ active chemical-assay pairs and an average of $12.2 / 20$ and 10.2/20 species impacted per chemical, respectively. The 2 assays the least affected were D2 and GABA-BZ with 386/1600 and 369/1600 active chemical-assay pairs and an average of 4.8/ 20 species impacted per chemical for both assays, respectively. 
Table 1. A summary of the significantly active chemical-assay pairs across the 20 species noted for each of the 80 test chemicals and 7 assays ${ }^{\mathrm{a}}$

\begin{tabular}{|c|c|c|c|c|c|c|c|c|}
\hline \multirow[b]{2}{*}{ Chemicals } & \multicolumn{7}{|c|}{$\%$ Species with significant hits for each chemical-assay pairing } & \multirow[b]{2}{*}{$\begin{array}{l}\text { Species-assay pairs affected by the } \\
\text { chemical listed }\end{array}$} \\
\hline & D2 & $\begin{array}{l}\text { GABA } \\
\text { BZ }\end{array}$ & NMDA & $\mathrm{mAChR}$ & AChE & GS & MAO & \\
\hline \multicolumn{9}{|l|}{ Metal(loid)s } \\
\hline $\mathrm{HgCl}$ & 70 & 55 & 25 & 80 & 90 & 60 & 95 & $95 / 140$ \\
\hline $\mathrm{Sn}$ & 20 & 75 & 45 & 95 & 65 & 65 & 85 & $90 / 140$ \\
\hline $\mathrm{MeHg}$ & 45 & 45 & 35 & 50 & 25 & 75 & 80 & $71 / 140$ \\
\hline $\mathrm{Ce}$ & 5 & 15 & 15 & 90 & 20 & 50 & 95 & $58 / 140$ \\
\hline $\mathrm{Pb}$ & 35 & 15 & 15 & 90 & 30 & 45 & 65 & $59 / 140$ \\
\hline $\mathrm{Ta}$ & 15 & 10 & 5 & 65 & 15 & 20 & 90 & $44 / 140$ \\
\hline $\mathrm{Y}$ & 55 & 30 & 10 & 15 & 20 & 90 & 35 & $51 / 140$ \\
\hline $\mathrm{Cu}$ & 10 & 10 & 20 & 45 & 40 & 50 & 65 & $48 / 140$ \\
\hline $\mathrm{Se}$ & 10 & 15 & 25 & 25 & 10 & 70 & 30 & $37 / 140$ \\
\hline $\mathrm{Cd}$ & 25 & 10 & 30 & 35 & 15 & 75 & 10 & $40 / 140$ \\
\hline $\mathrm{La}$ & 15 & 20 & 40 & 40 & 10 & 40 & 10 & $35 / 140$ \\
\hline $\mathrm{Cr}$ & 10 & 15 & 25 & 30 & 45 & 50 & 45 & $44 / 140$ \\
\hline As & 15 & 15 & 25 & 25 & 50 & 30 & 65 & $45 / 140$ \\
\hline $\mathrm{Mn}$ & 15 & 20 & 20 & 25 & 15 & 50 & 20 & $33 / 140$ \\
\hline Co & 15 & 15 & 20 & 20 & 80 & 60 & 20 & $46 / 140$ \\
\hline $\mathrm{Al}$ & 15 & 15 & 25 & 20 & 25 & 60 & 10 & $34 / 140$ \\
\hline $\mathrm{Li}$ & 5 & 15 & 15 & 10 & 20 & 45 & 40 & $30 / 140$ \\
\hline $\mathrm{Sc}$ & 15 & 15 & 0 & 20 & 15 & 15 & 70 & $30 / 140$ \\
\hline $\mathrm{Ni}$ & 10 & 5 & 15 & 40 & 85 & 15 & 45 & $43 / 140$ \\
\hline In & 10 & 5 & 15 & 40 & 25 & 25 & 25 & $29 / 140$ \\
\hline \multicolumn{9}{|c|}{ PAHs and halogentated organic compounds } \\
\hline Benzo[a]pyrene & 85 & 75 & 70 & 85 & 30 & 40 & 55 & $88 / 140$ \\
\hline Anthracene & 85 & 40 & 60 & 65 & 40 & 45 & 45 & $76 / 140$ \\
\hline $\begin{array}{l}1,2,5,6,9,10- \\
\text { Hexabromocyclododecane } \\
\text { (HBCD) }\end{array}$ & 70 & 20 & 70 & 40 & 25 & & & $45 / 100$ \\
\hline Aroclor 1248 & 15 & 35 & 25 & 25 & 20 & 100 & 40 & $52 / 140$ \\
\hline Trichloroethylene & 55 & 10 & 65 & 50 & 20 & & & $40 / 100$ \\
\hline Fluoranthene & 15 & 10 & 30 & 45 & 25 & 75 & 20 & $44 / 140$ \\
\hline Phenanthrene & 25 & 20 & 20 & 25 & 20 & 85 & 25 & $44 / 140$ \\
\hline Aroclor 1254 & 15 & 50 & 30 & 15 & 15 & 55 & 30 & $42 / 140$ \\
\hline Aroclor 1260 & 5 & 20 & 25 & 20 & 10 & 75 & 45 & $40 / 140$ \\
\hline Aroclor 1232 & 5 & 30 & 30 & 15 & 20 & 65 & 50 & $43 / 140$ \\
\hline Di-n-butyl phthalate solution & 30 & 60 & 40 & 25 & 25 & & & $36 / 100$ \\
\hline Aroclor 1016 & 0 & 25 & 30 & 15 & 25 & 65 & 45 & $41 / 140$ \\
\hline $\begin{array}{l}3,3^{\prime}, 5,5^{\prime} \text {-Tetrabromobisphenol A } \\
\text { (TBBPA) }\end{array}$ & 25 & 20 & 50 & 30 & 25 & & & $30 / 100$ \\
\hline $\begin{array}{l}\text { Tris(2-chloroethyl)phosphate } \\
\text { (TCEP) }\end{array}$ & 20 & 25 & 45 & 10 & 20 & & & $24 / 100$ \\
\hline $\begin{array}{l}\text { Tris(1-chloro-2-propyl) phosphate } \\
\text { (TCPP) }\end{array}$ & 15 & 15 & 30 & 25 & 45 & & & $26 / 100$ \\
\hline $\begin{array}{l}\text { Tris(1,3-dichloro-2-propyl) } \\
\text { phosphate (TDCPP) }\end{array}$ & 20 & 15 & 30 & 15 & 10 & & & $18 / 100$ \\
\hline Tricresyl phosphate (TCrP) & 15 & 15 & 20 & 10 & 35 & & & $19 / 100$ \\
\hline Dibromochloromethane solution & 15 & 25 & 5 & 25 & 40 & & & $22 / 100$ \\
\hline $\begin{array}{l}\text { Bis(2-ethylhexyl) phthalate } \\
\text { solution }\end{array}$ & 20 & 5 & 5 & 20 & 40 & & & $18 / 100$ \\
\hline Bromoform solution & 10 & 25 & 5 & 15 & 35 & & & $18 / 100$ \\
\hline $\begin{array}{l}\text { Tris(2-butoxyethyl)phosphate } \\
\text { (TBEP) }\end{array}$ & 15 & 20 & 10 & 5 & 40 & & & $18 / 100$ \\
\hline Fluoride & 15 & 5 & 5 & 10 & 15 & & & $10 / 100$ \\
\hline \multicolumn{9}{|l|}{ Pesticides } \\
\hline Prochloraz & 50 & 80 & 80 & 80 & 75 & 70 & 70 & $101 / 140$ \\
\hline Vinclozolin & 10 & 80 & 75 & 30 & 65 & 90 & 70 & $84 / 140$ \\
\hline Malathion & 65 & 35 & 35 & 45 & 75 & 75 & 70 & $80 / 140$ \\
\hline Methyl parathion & 40 & 30 & 35 & 40 & 70 & 70 & 65 & $70 / 140$ \\
\hline Parathion & 40 & 20 & 40 & 30 & 70 & 65 & 50 & $63 / 140$ \\
\hline Hexachlorocyclohexane $(\mathrm{HCH})$ & 40 & 35 & 45 & 40 & 25 & 50 & 60 & $59 / 140$ \\
\hline Fenitrothion & 40 & 25 & 15 & 30 & 20 & 60 & 65 & $51 / 140$ \\
\hline Diazinon & 30 & 15 & 25 & 0 & 15 & 80 & 65 & $46 / 140$ \\
\hline 1-Naphthyl-N-methylcarbamate & 30 & 30 & 5 & 15 & 15 & 80 & 60 & $47 / 140$ \\
\hline DDT & 25 & 20 & 25 & 10 & 45 & 80 & 60 & $53 / 140$ \\
\hline Dieldrin & 20 & 20 & 20 & 20 & 50 & 70 & 45 & $49 / 140$ \\
\hline DDE & 0 & 20 & 30 & 10 & 75 & 80 & 50 & $53 / 140$ \\
\hline Glyphosate & 0 & 25 & 20 & 30 & 75 & 40 & 35 & $45 / 140$ \\
\hline Fipronil & 20 & 5 & 5 & 15 & 15 & 85 & 20 & $33 / 140$ \\
\hline Lindane & 20 & 25 & 5 & 15 & 25 & & & $18 / 100$ \\
\hline \multicolumn{9}{|c|}{ Pharmaceuticals and personal care products } \\
\hline Diethylstilbesterol & 40 & 20 & 95 & 75 & 15 & 85 & 80 & $82 / 140$ \\
\hline $17 \alpha$-Ethinylestradiol & 30 & 15 & 100 & 95 & 15 & 30 & 75 & $72 / 140$ \\
\hline
\end{tabular}


Table 1. (Continued)

$\%$ Species with significant hits for each chemical-assay pairing

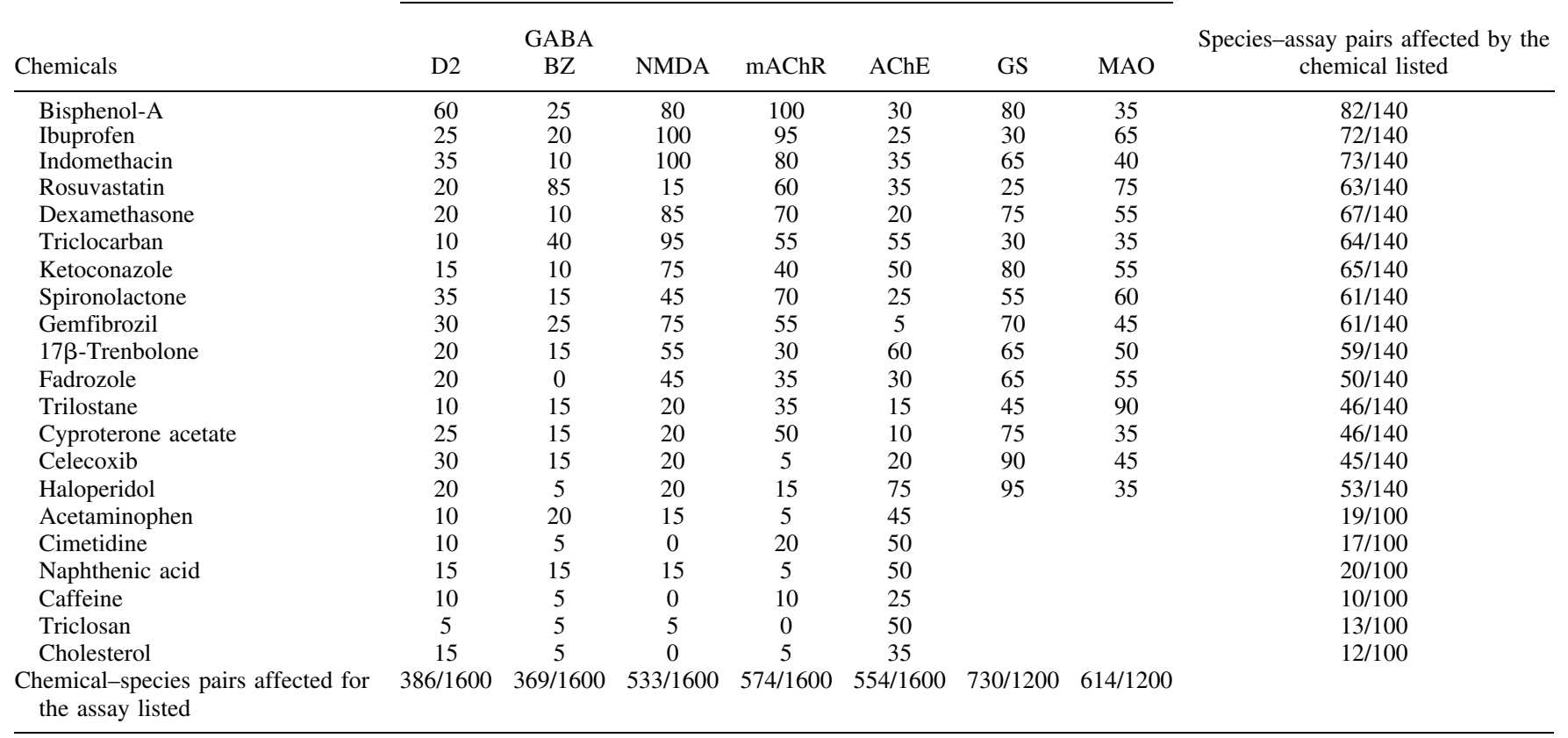

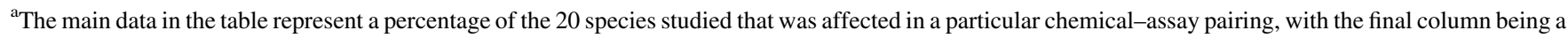
tally of the number of species-assay pairs significantly affected by the listed chemical and the final row being a tally of the number of chemical-species pairs significantly affected in the listed assay (within a chemical category, the chemicals are listed in rank order in terms of the number of "hits" found).

$\mathrm{AChE}=$ acetylcholine esterase $; \mathrm{D} 2=$ dopamine $-2 ; \mathrm{DDE}=$ dichlorodiphenyldichloroethylene; $\mathrm{DDT}=$ dichlorodiphenyltrichloroethane; $\mathrm{GABA} \mathrm{BZ}=$ gammaaminobutyric acid receptor benzodiazepine site; $\mathrm{GS}=$ glutamine synthetase; $\mathrm{mAChR}=$ muscarinic acetylcholine receptor; $\mathrm{MAO}=$ monoamine oxidase; $\mathrm{NMDA}=N$-methyl-d-aspartate; $\mathrm{PAH}=$ polycyclic aromatic hydrocarbon .

The chemical-assay responses were also subjected to clustering analyses (Figure 4). Eight clusters were identified and are briefly described. Clusters 1 to 4 consisted of chemical groupings that potentiated receptor binding or enzyme activity, while clusters 5 to 8 were chemicals that inhibited the assay responses. Cluster 1 included pesticides and PAHs $(r=0.85$; fenitrothion, malathion, 1-naphthyl- $N$-methylcarbamate, diazinon, phenanthrene, fluoranthene, Aroclor 1254, Aroclor 1248) that were associated with an increase in D2 receptor binding in multiple species (pilot whale, mink, common dolphin, bald eagle, polar bear, mouse, zebra finch, goldfish). Similarly, cluster 2 also documented an increase in D2 receptor binding for several chemicals in the same species listed in cluster 1 $(r=0.90$; DDE, glyphosate, parathion, Aroclor 1260, Aroclor 1016, Aroclor 1232, hexachlorocyclohexane, methyl parathion). Cluster 3 consisted of 2 PAHs, anthracene and benzo(a) pyrene. These 2 chemicals presented high similarities in terms of increasing D2 binding ( $r=0.74)$ in 14 out of 20 species (all species except for human, rat, rainbow trout, yellow perch, chicken, mallard) and for increased NMDA binding in 5 species (rat, mouse, common dolphin, river otter, Japanese quail). Cluster 4 included the 2 pharmaceuticals and personal care products ibuprofen and EE2 $(r=0.96)$, which potentiated NMDA binding in 14 out of 20 species assayed (all species except for rat, mouse, human, common dolphin, river otter, and Japanese quail). Cluster 5 consisted of different pesticides (fenitrothion, malathion, 1-naphthyl- $N$-methylcarbamate; $r=0.96)$ which inhibited GS activity in all species tested. Cluster 6 indicated that 2 pharmaceuticals (fadrazole, trilostane; $r=0.97)$ inhibited GS activity in all species tested. Cluster 7 grouped chemicals from different categories (BPA, prochloraz, spironolactone, $\mathrm{Sn}, \mathrm{Ce}, \mathrm{Ta} ; r=0.88$ ), and in vitro exposure to those chemicals resulted in an inhibition of mAChR binding in 15 out of 20 species (all species except for rat, yellow perch, bald eagle, zebra finch, Japanese quail). Cluster 8 included pesticides and PAHs (DDE, glyphosate, parathion, Aroclor 1260, Aroclor 1016, Aroclor 1232, hexachlorocyclohexane, methyl parathion; $r=0.97$ ) which inhibited AChE activity in 13 species out of 20 (pilot whale, common dolphin, yellow perch, rainbow trout, king mackerel, yellowfin tuna, bald eagle, zebra finch, chicken, Japanese quail, mallard, rat, mouse).

The chemical-assay clustering data set (as well as the other results) presented provides a rich amount of information that can be used to help better screen environmental chemicals, prioritize and focus future activities, explore potential differences across a diverse number of species, read across chemicals or species, and develop new hypotheses. While the information contained in the previous paragraph points to similar clusters, it is important to observe the exceptions, particularly for species from the same taxonomic group (i.e., are they really different, or are there technical errors underlying these assays?) and for chemicals with well-established modes of action. One may reasonably expect that responses elicited by a given chemical would cut across species (especially within a taxa), and this was seldom observed (only in clusters 5 and 6), thus leading us to recognize a need to better characterize assay sensitivity and specificity (true/false and positive/negative findings).

While it is not feasible to explore all the results in detail, 3 examples are highlighted. First, the 4 PAHs included in our screening activity were associated with increased D2 receptor binding in most species. These chemicals have traditionally not been considered as being neuroactive, though more attention is being paid to their potential neurodevelopmental effects [22]. Given the ubiquity of PAHs in the environment (e.g., air pollution, coal tar sealants, oil spills), more research on potential 


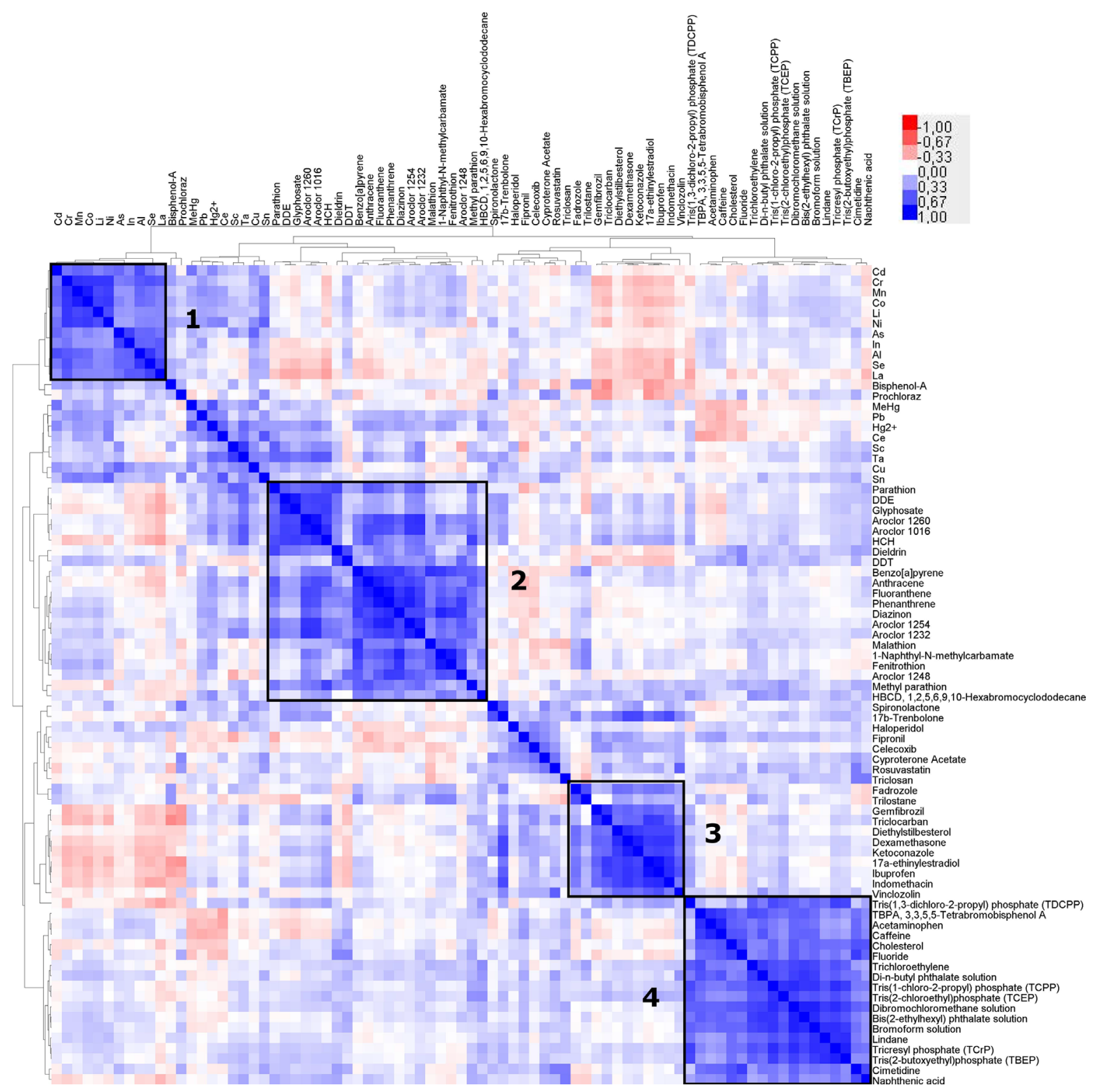

Figure 2. Clustering of neurochemical cell-free assay results across 20 species against 80 chemicals based on chemical-chemical similarity matrix (Euclidean distance, complete linkage). The strength of associations is visualized in the heat map from red (negative associations) to blue (positive associations). Chemicals clustered along the diagonal have the highest associations. Four key clusters were identified.

neurodevelopmental effects toward a range of ecological species may be fruitful. Second, there is growing interest in using readacross methods particularly for chemicals with limited data. In the present study we included 5 organophosphate flame retardants (TCPP, TCEP, TCrP, TBEP, TDCPP) which have been promoted as replacements for brominated flame retardants yet for which there exists limited toxicological information. Our in vitro screen shows that these chemicals acted quite similarly, thus supporting the potential use of read-across for chemicals with similarities in structure. Third, we point to a situation in which we expected an inhibitory response to cut across all species. We indicated that cluster 8 chemicals inhibited AChE activity in 13 out of 20 species and that one of the chemicals in this cluster was parathion, which is a potent $\mathrm{AChE}$ inhibitor. The present study did not show in vitro effects of parathion toward $\mathrm{AChE}$ in the brain extracts from human, river otter, mink, goldfish, polar bear, narwhal, or ringed seals, even though wholeanimal studies have shown parathion-related inhibitions in humans [23] and goldfish [24]. This particular case raises concerns about assay validity and a particular need to include positive chemicals, link in vitro and in vivo data sets, and ultimately strive toward continuing to improve the method.

\section{Limitations and future directions}

The cost/performance ratio of these cell-free assays makes them attractive as tools to screen, prioritize, and evaluate a large number of chemicals and environmental mixtures and thus help potentially meet regulatory obligations as well as help satisfy societal concerns. Despite this promise, there are challenges with cell-free assays that warrant mention. Foremost is that the assays represent a simple biological system. They lack the basic cellular machinery found in traditional in vitro models such as cell lines and cell cultures, yet one may argue that they may be more relevant models than can be achieved in silico. They lack the metabolic capacity of cells, though future endeavors could aim to increase their realism via coincubations with biological 
Table 2. For each of the 20 species studied, the number of significantly active chemical-assay pairs is summarized as well as the number of active chemicals and assays $^{\mathrm{a}}$

\begin{tabular}{lccc}
\hline Species & Active chemical-assay pairs & Active chemicals & Active assays \\
\hline Yellow perch & $237 / 540$ & $79 / 80$ & $7 / 7$ \\
Pilot whale & $236 / 540$ & $78 / 80$ & $70 / 80$ \\
Human & $233 / 540$ & $74 / 80$ & $7 / 7$ \\
Rainbow trout & $229 / 540$ & $79 / 80$ & $7 / 7$ \\
River otter & $221 / 540$ & $76 / 80$ & $7 / 7$ \\
Yellowfin tuna & $213 / 540$ & $77 / 80$ & $7 / 7$ \\
Chicken & $212 / 540$ & $76 / 80$ & $7 / 7$ \\
Mallard & $207 / 540$ & $78 / 80$ & $7 / 7$ \\
Mink & $206 / 540$ & $78 / 80$ & $7 / 7$ \\
King mackerel & $199 / 540$ & $77 / 80$ & $7 / 7$ \\
Japanese quail & $197 / 540$ & $76 / 80$ & $7 / 80$ \\
Goldfish & $197 / 540$ & $71 / 80$ & $7 / 7$ \\
Common dolphin & $191 / 540$ & $77 / 80$ & $7 / 70$ \\
Rat & $190 / 540$ & $73 / 80$ & $7 / 7$ \\
Polar bear & $188 / 540$ & $72 / 80$ & $7 / 7$ \\
Bald eagle & $186 / 540$ & $76 / 80$ & $7 / 7$ \\
Mouse & $185 / 540$ & $76 / 80$ & $7 / 7$ \\
Narwhal & $182 / 540$ & $74 / 80$ & $7 / 7$ \\
Ringed seal & $166 / 540$ & $166 / 540$ & $7 / 7$ \\
Zebra finch & $165 / 7$ \\
\hline
\end{tabular}

aThe species are listed in decreasing rank order in terms of active "hits".

cofactors (e.g., S9 fractions). Moving forward, validation studies that enable comparisons between in vitro data from cell-free assays and physiological responses from the whole organism are required to establish these in vitro testing tools as being reliable and predictive. However, there are challenges with such a notion given that most of the species in the present study are not conducive to being tested in an experimental setting in which neurotoxicity (and other apical measures) can be taken.

The present study serves as a proof of concept that can be improved on in many regards. For example, some technical

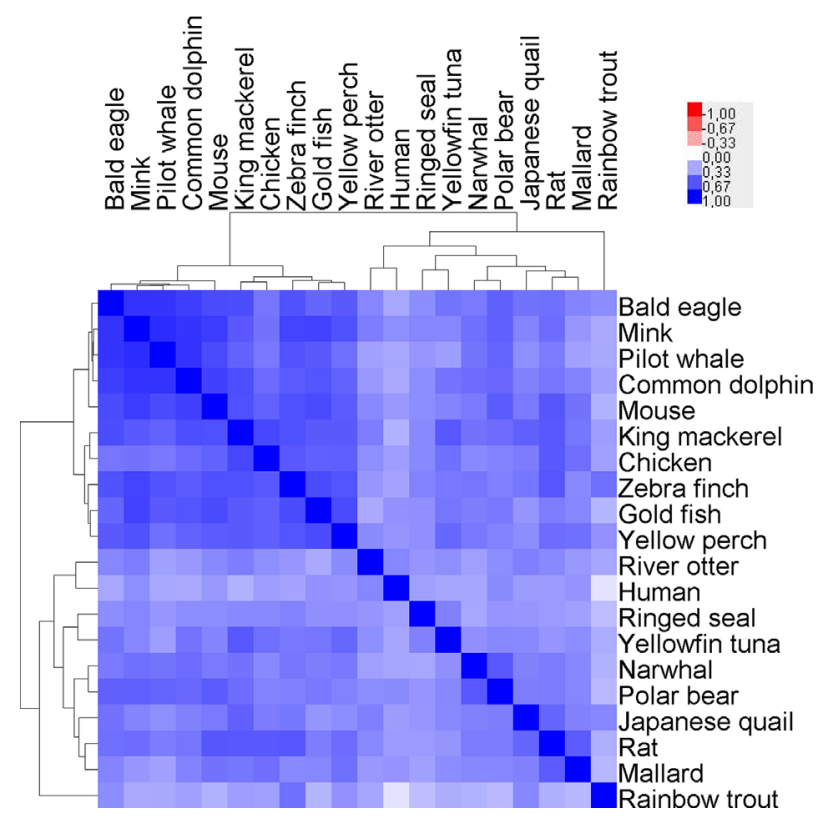

Figure 3. Clustering of neurochemical cell-free assay results across 20 species against 80 chemicals based species-species similarity matrix (Euclidean distance, complete linkage). The strength of associations is visualized in the heat map from light blue (strongest positive associations) to dark blue (weakest positive associations). Species clustered along the diagonal have datasets with the highest associations. challenges were outlined previously, and these can be carefully monitored and potentially remedied by the use of several quality control mechanisms. As part of a screening effort that mirrors an approach taken by the USEPA's ToxCast program, we only tested a single concentration (i.e., $50 \mu \mathrm{M}$ ) of each chemical. While this is a reasonable start, testing a single value at a relatively high concentration represents at best a first-tier screening approach. Positive hits need to be retested at a range of concentrations to help understand response potency and efficacy as well as points of departure and to buffer against potential false-positive results. Conversely, test chemicals that do not elicit a response at $50 \mu \mathrm{M}$ need to be tested at different concentrations, especially lower ones, given the possibility of nonmonotonic concentration-response profiles. Because the assay is being hailed as one that has high-throughput potential, scaling up the number of concentrations tested should not be difficult but nonetheless requires added resources and careful consideration. Beyond testing multiple concentrations of a given chemical, future efforts could address the possibility of studying complex mixtures as done in previous efforts $[10,11]$.

The present study was narrowly focused on select neurochemicals; moving ahead, the number of cell-free assays can be expanded to increase the size of the biological space that can be interrogated. The neurochemical systems investigated are conducive to being modeled into an adverse outcome pathway framework, and future efforts could strive toward developing predictive models whereby cell-free results serve as molecular initiating events and are linked quantitatively to apical outcomes of regulatory interest [25]. Such modeling activities hold great promise though will also require careful validation studies, particularly through wholeanimal studies on select cases to show a linkage between the in vitro and in vivo results. We focused on a relatively small number of well-studied chemicals, and future work can embark on screening a larger library of chemicals as well as complex environmental mixtures. Tools that can screen and prioritize a large number of samples are sorely needed in the field of environmental toxicology. 


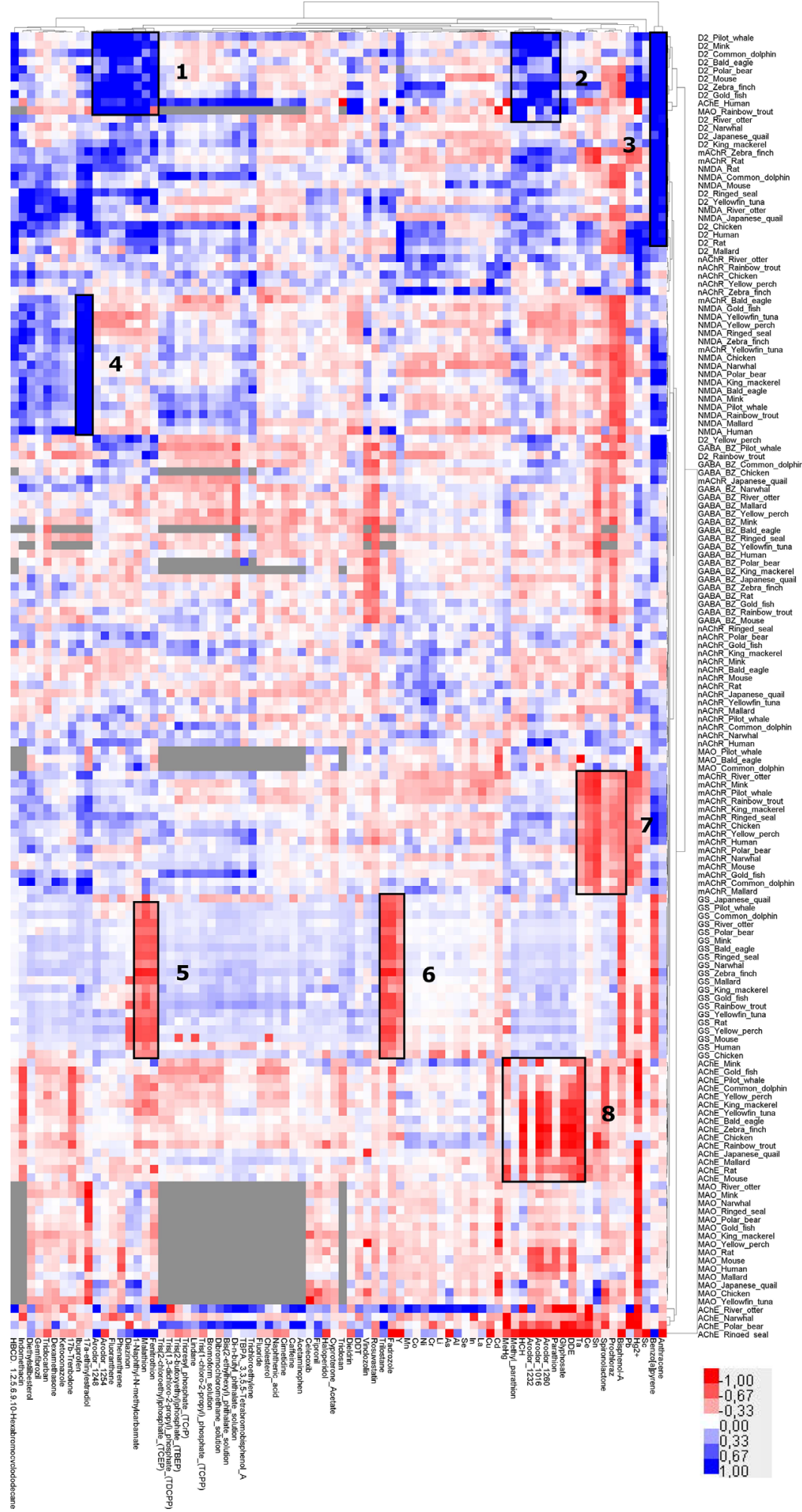

Figure 4. Hierarchical clustering of 80 chemicals by 8 assays and 20 species (Euclidean distance, complete linkage). The cluster is based on chemical-assay potency as measured by the relative percentage of binding/activity compared to nonexposed controls. The strength of associations is visualized in the heat map with gray cells indicating no change, red cells indicating inhibition, and blue cells indicating activation. Eight key clusters were identified.

\section{CONCLUDING REMARKS}

There is a great need worldwide (by regulatory agencies and industries alike) to accelerate the development and application of new approach methodologies, including in vitro toxicity testing tools for the purposes of ecological risk assessment [5].
We have previously developed and applied neurochemicalbased, cell-free assays to screen environmental mixtures $[10,11]$ and chemicals $[12,13]$ against a range of ecological species including some that are very difficult to study such as ringed seals [13]. We scaled up our activities to apply a set of 7 cell-free neurochemical screening assays to serve as a screening platform 
to evaluate 80 chemicals across 20 species. In general, the results show that cell-free tests may be an attractive tool to predictive ecotoxicology, especially given the limited availability of test organisms (particularly species that are at risk, difficult to maintain in captivity, etc.), lack of proven cell-based tools (e.g., primary and cell-line based cultures), societal concerns over animal testing, and the sheer number of ecological species to study as well as vast interspecies differences that pose barriers. Performing comparable research in whole animals would have taken many years and millions of dollars. Despite potential benefits, there are key limitations that must be recognized, and future work is needed to demonstrate that these assays are indeed useful to end-user groups.

Supplemental Data-The Supplemental Data are available on the Wiley Online Library at DOI: 10.1002/etc.3880.

Acknowledgment-The present study was funded by grants from the USEPA's Science to Achieve Results Program (award R835170), the Natural Sciences and Engineering Research Council of Canada's Discovery Grants Program, and the Canada Foundation for Innovation's Leaders Opportunity Fund (all to N .Basu). We thank J. Eng and J. Pawly for technical assistance as well as 2 anonymous reviewers for providing constructive feedback. We acknowledge the donation of human brain tissues from the Cooperative Human Tissue Network as well as other organizations listed in Supplemental Data, Table S1. We acknowledge the donation of test chemicals from D. Villeneuve (USEPA's Mid-Content Ecology Division, Duluth, MN) as well as his comments on the manuscript. The authors have no conflicts of interest to declare.

\section{REFERENCES}

1. Collins FS, Gray GM, Bucher JR. 2008. Transforming environmental health protection. Science 319:906-907.

2. Judson R, Richard A, Dix DJ, Houck K, Martin M, Kavlock R, Dellarco V, Henry T, Holderman T, Sayre P, Tan S, Carpenter T, Smith E. 2009. The toxicity data landscape for environmental chemicals. Environ Health Persp 117:685-695.

3. Kavlock RJ, Austin CP, Tice RR. 2009. Toxicity testing in the 21st century: Implications for human health risk assessment. Risk Anal 29:485-487.

4. National Research Council. 2007. Toxicity testing in the 21 st century: A vision and a strategy. Washington, DC

5. Villeneuve DL, Garcia-Reyero N. 2011. Vision \& strategy: Predictive ecotoxicology in the 21st century. Environ Toxicol Chem 30:1-8.

6. Head JA, Hahn ME, Kennedy SW. 2008. Key amino acids in the aryl hydrocarbon receptor predict dioxin sensitivity in avian species. Environ Sci Technol 42:7535-7541.

7. Vardy DW, Oellers J, Doering JA, Hollert H, Giesy JP, Hecker M. 2013. Sensitivity of early life stages of white sturgeon, rainbow trout, and fathead minnow to copper. Ecotoxicology 22:139-147.

8. Knudsen TB, Houck KA, Sipes NS, Singh AV, Judson RS, Martin MT, Weissman A, Kleinstreuer NC, Mortensen HM, Reif DM, Rabinowitz JR, Setzer RW, Richard AM, Dix DJ, Kavlock RJ. 2011. Activity profiles of 309 ToxCast ${ }^{\mathrm{TM}}$ chemicals evaluated across 292 biochemical targets. Toxicology 282:1-15.

9. Judson RS, Houck KA, Kavlock RJ, Knudsen TB, Martin MT, Mortensen HM, Reif DM, Rotroff DM, Shah I, Richard AM, Dix DJ. 2010. In vitro screening of environmental chemicals for targeted testing prioritization: The ToxCast project. Environ Health Persp 118:485-492.
10. Basu N, Ta CA, Waye A, Mao J, Hewitt M, Arnason JT, Trudeau VL. 2009. Pulp and paper mill effluents contain neuroactive substances that potentially disrupt neuroendocrine control of fish reproduction. Environ Sci Technol 43: 1635-1641.

11. Arini A, Cavallin JE, Berninger JP, Marfil-Vega R, Mills M, Villeneuve DL, Basu N. 2016. In vivo and in vitro neurochemical-based assessments of wastewater effluents from the Maumee River area of concern. Environ Pollut 211:9-19.

12. Basu N, Stamler CJ, Loua KM, Chan HM. 2005. An interspecies comparison of mercury inhibition on muscarinic acetylcholine receptor binding in the cerebral cortex and cerebellum. Toxicol Appl Pharm 205:71-76.

13. Basu N, Kwan M, Chan HM. 2006. Mercury but not organochlorines inhibits muscarinic cholinergic receptor binding in the cerebrum of ringed seals (Phoca hispida). J Toxicol Env Heal A 69:1133-1143.

14. Rutkiewicz J, Bradley M, Mittal K, Basu N. 2013. Methylmercury egg injections: Part 2. Pathology, neurochemistry, and behavior in the avian embryo and hatchling. Ecotox Environ Safe 93:77-86.

15. Rutkiewicz J, Nam DH, Cooley T, Neumann K, Padilla IB, Route W, Strom S, Basu N. 2011. Mercury exposure and neurochemical impacts in bald eagles across several Great Lakes states. Ecotoxicology 20:1669-1676.

16. The Government of Canada and the Government of the United States. Great Lakes Water Quality Agreement. 2012. Protocol Amending the Agreement Between Canada and the United States of America on Great Lakes Water Quality, 1978, as Amended on October 16, 1983, and on November 18, 1987. Enacted February 12, 2013. Gatineau, QC, Canada; Chicago, IL, USA.

17. Muir D, Howard PH, Meylan W. 2008. Identification of new, possible PB\&T substances important in the Great Lakes region by screening of chemicals in commerce. [cited 2017 June 1]. Available from: https:// archive.epa.gov/greatlakes/p2/web/pdf/pbtreport.pdf

18. US Congress. 1980. Comprehensive Environmental Response, Compensation, and Liability Act (CERCLA) and Federal Facilities, Pub. L. No. 96-510 (December 11, 1980). Washington, DC.

19. Kolpin DW, Furlong ET, Meyer MT, Thurman EM, Zaugg SD, Barber LB, Buxton HT. 2002. Pharmaceuticals, hormones, and other organic wastewater contaminants in U.S. streams, 1999-2000: A national reconnaissance. Environ Sci Technol 36:1202-1211.

20. Centers for Disease Control and Prevention. 2009. Forth National Report of Human Exposures to Environmental Chemicals. Department of Health and Human Services, Atlanta, GA, USA.

21. Sipes NS, Martin MT, Reif DM, Kleinstreuer NC, Judson RS, Singh AV, Chandler KJ, Dix DJ, Kavlock RJ, Knudsen TB. 2011. Predictive models of prenatal developmental toxicity from ToxCast highthroughput screening data. Toxicol Sci 124:109-127.

22. Slotkin TA, Skavicus S, Card J, Giulio RT, Seidler FJ. 2017. In vitro models reveal differences in the developmental neurotoxicity of an environmental polycylic aromatic hydrocarbon mixture compared to benzo $[a]$ pyrene: Neuronotypic PC12 cells and embryonic neural stem cells. Toxicology 377:49-56.

23. Eyer F, Meischner V, Kiderlen D, Thiermann H, Worek F, Haberkorn M, Felgenhauer N, Zilker T, Eyer P. 2003. Human parathion poisoning. A toxicokinetic analysis. Toxicol Rev 22:143-163.

24. Ferrari A, Venturino A, de D'Angelo AM. 2004. Time course of brain cholinesterase inhibition and recovery following acute and subacute azinphosmethyl, parathion and carbaryl exposure in the goldfish (Carassius auratus). Ecotox Environ Safe 57:420-425.

25. Watanabe K, Anderson M, Basu N, Carvan MJ 3rd, Crofton KM, King KA, Suñol C, Tiffany-Castiglioni E, Schultz IR. 2011. Defining and modeling known adverse outcome pathways: Domoic acid and neuronal signaling as a case study. Environ Toxicol Chem 30:9-21. 